\title{
Formação continuada dos professores e o uso das novas tecnologias em escolas públicas do Rio de Janeiro
}

\author{
Ana Márcia da Silva Vieira (MPNTDE | UniCarioca) \\ Débora Alves Morra Loures (MPNTDE | UniCarioca) \\ Paloma Mendes Flores Brandão (MPNTDE | UniCarioca) \\ Ana Paula Legey (NUCAP | MPNTDE | UniCarioca) \\ Antônio Carlos Mol (NUCAP | MPNTDE | UniCarioca | IEN | CNEN) \\ Marcos Antônio Silva (MPNTDE | UniCarioca) \\ Victor Gonçalves Freitas (NUCAP | MPNTDE | UniCarioca)
}

\section{Resumo}

A partir do reconhecimento das novas tecnologias digitais na sociedade atual e dos benefícios e avanços que podem trazer para a educação, este trabalho investiga como se encontra a formação do professor para atuar em sala de aula com essas novas ferramentas e quais tecnologias estão presentes no âmbito escolar. A metodologia utilizada é a de abordagem qualitativa e quantitativa, mediante a aplicação e tabulação dos resultados realizados através de uma entrevista com professores da Educação Básica do Município do Rio de Janeiro. Os resultados obtidos evidenciaram a falta de preparo profissional e de oferta em relação à formação inicial e continuada, as quais não fomentam o ensino e a aplicabilidade dos recursos, assim como, a deficiência em relação à falta de disponibilização dos recursos tecnológicos nas escolas. Para melhorar este quadro, foi apresentado um jogo educativo denominado "Estrela do Saber", de modo a sensibilizar a prática educativa do professor, permitindo assim, um contato inicial com as novas tecnologias digitais, incluindo os benefícios que o recurso pode oferecer.

Palavras-chave: Educação; Formação Continuada; Jogos digitais; Novas tecnologias.

\begin{abstract}
From the recognition of the new digital technologies in current society and the benefits and advances that they can bring to education, this work investigates in which state is the qualification of teachers to act in classrooms with these new tools and which technologies are present in the school scope. The methodology used is of quantitative and qualitative approach upon application and tabulation of results obtained through an interview with teachers of Basic Education from Rio de Janeiro. The results obtained have evidenced the lack of professional prepare and supply in relation to initial and continued formation, which do not promote the teaching and applicability of resources, as well as the deficiency in relation to the lack of availability of technological resources in schools. To improve this situation, an educational game named "Estrela do Saber" was presented in order to sensitize the teacher's educational practice, thus allowing an initial contact with the new digital technologies, including the benefits that it can provide.
\end{abstract}

Keywords: Education; Continued Formation; Digital Games; New Technologies.

\section{Introdução}

As novas tecnologias já constituem parte cultural da sociedade atual. Tal afirmativa permite uma reflexão acerca da concepção de escola e de educação. Elas estão sendo capazes de permear estas novas estruturas de sociedade, que se mantém cada vez mais indissociável aos aportes tecnológicos.

Esta pesquisa tem por finalidade investigar a formação dos professores da Educação Básica de escolas públicas do Município do Rio de Janeiro para que possamos compreender o real motivo da dissociação da prática pedagógica com as novas tecnologias, trazendo para a discussão as dificuldades, ansiedades e angústias dos educadores, bem como a falta de conhecimentos pertinentes à utilização delas e/ou a falta de equipamentos e softwares capazes de atender a esta nova demanda de alunos. 
O estudo em questão procurou verificar se os professores da Educação Infantil ao quinto ano de escolaridade, pertencentes a escolas públicas do município do Rio de Janeiro, possuem ferramentas digitais presentes em sala de aula, se utilizam as tecnologias em suas aulas e como se dá o processo de formação continuada do docente.

Para promover o encontro do professor com ferramentas tecnológicas motivadoras e significativas para a aprendizagem, houve a sensibilização dos participantes desta pesquisa à utilização de um recurso digital, sendo apresentado e aplicado o jogo digital "Estrela do Saber", desenvolvido pelo NUCAP - Núcleo de Computação Aplicada do Centro Universitário UniCarioca, enfatizando o uso desta ferramenta inovadora, fazendo com que os professores percebam a importância e a utilização das novas tecnologias.

\section{Abordagem Metodológica}

A presente pesquisa caracteriza-se como pesquisa exploratória abordada de forma descritiva, na qual é investigada a ação do professor e o uso das tecnologias no processo de ensino aprendizagem, considerando a possibilidade de existência de formação continuada em serviço.

Os instrumentos utilizados para o levantamento e coleta de dados foram um questionário composto por questões de caracterização e outras constituídas por uma série ordenada de perguntas fechadas, além de entrevista realizada com professores regentes que lecionam nas escolas públicas do Município do Rio de Janeiro.

O questionário, composto por nove questões, foi aplicado pessoalmente pelos integrantes do grupo de trabalho, através de contato direto com os professores, podendo, assim, sanar dúvidas sobre o preenchimento de algumas questões.

Para subsidiar o trabalho foram utilizadas duas técnicas distintas na pesquisa de campo. A primeira foi a coleta de dados para verificar e avaliar como se encontra o processo de formação continuada do professor e o uso das tecnologias digitais em sala de aula; a segunda técnica desenvolvida foi realizada através de um trabalho de sensibilização com o professor para aplicabilidade do jogo digital Estrela do Saber, como ferramenta tecnológica para aferir o conhecimento de um recurso digital, a aceitação, usabilidade e aplicabilidade em serviço.

O recurso selecionado foi um jogo digital educativo, pois se observa que atualmente esses recursos têm se tornado uma estratégia didática que auxilia o professor em sala de aula, portanto uma excelente ferramenta tecnológica para ser trabalhada com o aluno em diversas áreas do conhecimento.

Descreveremos neste trabalho a investigação da temática Formação de Professor Frente às Novas Tecnologias, Jogo digital como ferramenta pedagógica, apresentando também as competências, os resultados das entrevistas e a aplicabilidade dos jogos com professores participantes desta pesquisa.

\section{Educação e Novas Tecnologias}

As tecnologias são construídas a partir da sociedade e ganham significados a partir da sua relação com a cultura e com os grupos sociais, com a qualidade didática das práticas pedagógicas desenvolvidas na escola. Nesse sentido, Levy (1999) afirma que

(...) não se trata aqui de usar as tecnologias a qualquer custo, mas sim de acompanhar consciente e deliberadamente uma mudança de civilização que questiona profundamente as formas institucionais, as mentalidades e a cultura dos sistemas educacionais tradicionais e, sobretudo, os papeis de professor e de aluno (p.172).

A construção da proposta pedagógica da escola precisa contemplar as novas tecnologias digitais para que os processos educativos permitam conexões entre educação, formação e tecnologias.

Kenski (2012, p.18) descreve que "a educação também é um mecanismo poderoso de articulação das relações entre poder, conhecimento e tecnologias", além disso, "a escola representa na sociedade moderna o espaço de formação não apenas das gerações jovens, mas de todas as pessoas”. 
Entretanto o espaço de formação não pode ser um espaço remoto, porque as novas ferramentas tecnológicas estão inseridas no processo de ensino e aprendizagem; a todo o momento, é necessário fomentar a criação de práticas inovadoras enriquecendo pedagogicamente a construção e produção do saber educativo e cultural.

Portanto, novas práticas e recursos tecnológicos devem ser aplicados no processo de ensino-aprendizagem, como um novo recurso educativo, explorando através das ferramentas digitais novos paradigmas pedagógicos, objetivando transformar a educação tradicional em uma educação emancipadora através da oferta da diversidade, da cultura, do imaginário, utilizando inúmeras fontes de informações trabalhadas sob a mediação professor e aluno.

De acordo com os Parâmetros Curriculares Nacionais (2000), no que tange às questões relacionadas às tecnologias e comunicação:

As novas tecnologias da comunicação e da informação permeiam o cotidiano, independente do espaço físico, e criam necessidades de vida e convivência que precisam ser analisadas no espaço escolar. A televisão, o rádio, a informática, entre outras, fizeram com que os homens se aproximassem por imagens e sons de mundos antes inimagináveis. (...) Os sistemas tecnológicos, na sociedade contemporânea, fazem parte do mundo produtivo e da prática social de todos os cidadãos, exercendo um poder de onipresença a, uma vez que criam formas de organização e transformação de processos e procedimentos (PCN 2000, p.11-12).

Neste sentido, o uso das novas tecnologias na educação está implícito no cotidiano escolar, com desdobramentos antes impossíveis de serem imagináveis. Sendo assim, a educação precisa oportunizar e considerar a vivência de múltiplos locais de aprendizagem, de maneira a se projetar além do espaço físico escolar. Segundo Kenski (2012, p.43), "a educação e tecnologias são indissociáveis".

Os desafios na constituição de tempo e espaço às novas tecnologias digitais na educação perpassam da gestão de aquisição de informação para a gestão significativa do conhecimento. Na atualidade, a educação formal ofertada pela escola regular continua utilizando as mesmas estratégias didáticas e pedagógicas no contexto tradicional, através de metodologias e ferramentas descontextualizadas em sala de aula.

Tal observação está relacionada a fatos cotidianos observados em sala de aula, como carteiras enfileiradas, livros impressos, aulas expositivas através da transmissão de conteúdos, despreparo dos professores quanto à temática da aprendizagem e sua relação com a formação das novas tecnologias digitais na educação por falta de preocupação e/ou preparo do professor.

\section{Formação continuada do professor e as novas tecnologias}

A formação dos professores a partir de inovações tecnológicas, culturais e sociais é fundamental. Uma das ações que envolvem essa atualização é o processo de formação continuada que, segundo Almeida (2005), "para que o professor possa expandir o seu olhar para outros horizontes, e desenvolver competências, é importante que ele esteja engajado em programas de formação continuada”.

O papel do professor não será substituído pelas novas tecnologias. Portanto, o processo de formação continuada precisa atender à renovação tecnológica dos tempos atuais, contemplando o ensino e o aperfeiçoamento do uso das novas tecnologias em sala de aula. Assim, os professores poderão romper as barreiras digitais no espaço formal da aprendizagem.

De acordo com Moran (1999),

muitas formas de ensinar hoje não se justificam. Perdemos tempo demais, aprendemos muito pouco, nos desmotivamos continuamente. Tanto professores como alunos têm a clara sensação de que muitas aulas convencionais estão ultrapassadas. Mas, para onde mudar? Como ensinar e aprender em uma sociedade mais interconectada. (p. 1. 1999)

A tecnologia não é mais considerada apenas como um instrumento, pois passou a fazer parte da estrutura social e educacional que nela se apoia e se transforma, ou seja, observa-se uma mudança cultural da sociedade.

Os programas de formação continuada na educação devem estar agregados aos recursos digitais para permitir sua plena utilização, principalmente na sala de aula. Torna-se necessário então respondermos à seguinte questão: "como o professor vai utilizar os recursos digitais, se ele não é letrado digitalmente?". 
De acordo com Buzato (2006):

Letramentos digitais (LDs) são conjuntos de letramentos (práticas sociais) que se apoiam, entrelaçam e apropriam mútua e continuamente por meio de dispositivos digitais para finalidades específicas, tanto em contextos socioculturais geograficamente e temporariamente limitados, quanto naqueles construídos pela interação mediada eletronicamente (BUZATO, 2006 apud FREITAS, 2010).

Nesse sentido, o letramento digital pode ser considerado como a utilização de recursos tecnológicos inseridos em novas práticas pedagógicas e sociais, contemplando as múltiplas competências e habilidades, e não somente conhecimento técnico. Daí a necessidade da formação continuada do professor que está presente em sala de aula.

As discussões sobre a temática do processo de formação continuada com ênfase nas novas tecnologias digitais inseridas no processo educacional preparam o professor para aprender mais sobre o letramento digital e não apenas disponibilizar cursos de informática educativa online.

Tais discussões podem ser consideradas processos diferenciados em que o professor através de novas ferramentas tecnológicas reaprenderá a elaborar planos de aula com novas metodologias, assim como técnicas que estarão em consonância com a nova sociedade da informação que hoje está presente nas escolas.

Como descrito por Lévy (1999), professor e alunos tornam-se protagonistas do processo educativo, quando o papel do professor passa a permear a ideia de se considerar:

Um animador de inteligência coletiva dos grupos que estão a seu encargo. Sua atividade será concentrada no acompanhamento e na gestão das aprendizagens: o incitamento à troca de saberes, a mediação relacional e simbólica, a pilotagem personalizada dos percursos de aprendizagem etc. (LÉVY, 1999- p.171).

Em suma, o processo de formação continuada do professor, atrelado ao uso das novas tecnologias, apresenta múltiplos desafios que envolvem a todo tempo políticas públicas, financiamento, gestão escolar, o papel do educador, a comunidade escolar e, principalmente, o aluno. O professor precisa estar capacitado para utilizar os recursos tecnológicos e suas interfaces de forma crítica e pedagógica. Observamos assim a importância do processo de formação continuada no que tange às novas ferramentas digitais que promovem a aprendizagem.

\section{Jogos digitais como ferramenta pedagógica}

A inclusão digital nas escolas já não é mais uma vontade, mas sim uma realidade social, cultural, educacional e tecnológica. As novas ferramentas digitais estão presentes em todas as ações do homem no mundo moderno.

A criança tem a necessidade de aprender de forma lúdica, didática e prazerosa. Ela precisa ser provocada e instigada a aprender a aprender, para poder no futuro enfrentar os desafios que a vida oferece para todos.

Nos tempos atuais, os jogos educativos são considerados como programa ou como uma estratégia metodológica, que, ao serem trabalhados pelo professor de forma contextualizada no processo ensino-aprendizagem, acaba unindo as características dos jogos com as de softwares e conteúdos didáticos. Ou seja, o jogo digital, se bem trabalhado, enriquece, inova e renova as estratégias tecnológicas utilizadas em sala de aula.

Conforme afirma Prikladnicki e Wangenheim (2008, p.37),

com o desenvolvimento de novas tecnologias, os jogos se tornaram um aliado para a sala de aula, permitindo que o ambiente educacional, saia do ensino tradicional e passe a funcionar dentro da informação. Logo, o uso de jogos para treinar, aprender e executar atividades reais em ambientes virtuais pode melhorar o desempenho dos estudantes, pois possibilita a vivência de experiências de aprendizagem produzidas individualmente de acordo com o estilo do estudante (PRIKLADNICKI e WANGENHEIM, 2008, p.37).

É importante ressaltar que, como ferramenta tecnológica, o jogo digital é capaz de auxiliar e motivar professores de diferentes instâncias à utilização dos recursos tecnológicos, em que a interação e participação de diferentes professores, através da exposição das experiências, permitirão o enriquecimento de diferentes ideias, dando corpo ao projeto e permitindo uma nova visão e utilização dos recursos em sua plenitude, sendo respeitados os recursos tecnológicos existentes em cada instância, tirando melhor proveito possível de cada um. 
Para isso, apresentamos nesta pesquisa o jogo digital Estrela do Saber como proposta de uma ferramenta pedagógica a ser utilizada pelos professores em sala de aula.

\section{Jogo digital Estrela do Saber/NUCAP/UniCarioca}

Diante de toda premissa observada neste trabalho e visando buscar uma percepção de educação, que seja moderna e que permita novos modos de atuação do professor, principalmente no que se refere à utilização dos recursos tecnológicos em sala de aula, inserimos na sequência didática desta pesquisa a aplicabilidade de um jogo digital chamado Estrela do Saber, desenvolvido pelo NUCAP- Núcleo de Computação Aplicada do Centro Universitário UniCarioca.

A apresentação deste jogo digital nesta pesquisa visa contemplar o objetivo geral, porque investiga a utilização de um recurso pertencente às novas tecnologias como forma de contribuição para o enriquecimento do processo de formação continuada do professor e o domínio dele com as interfaces tecnológicas renovando, assim, a sua prática docente.

O jogo digital Estrela do Saber do NUCAP/UniCarioca, apresentado aos sujeitos desta pesquisa, é composto de perguntas e respostas contendo uma série de desafios. Contém um recurso chamado Modo Professor, que possibilita editar as perguntas/respostas, dando ao professor a possibilidade de modificar as perguntas do jogo de acordo com o conteúdo trabalho em sala de aula. Não é necessário ter internet, e o professor pode salvá-lo em um pendrive ou em um tablet e disponibilizá-lo para os alunos.

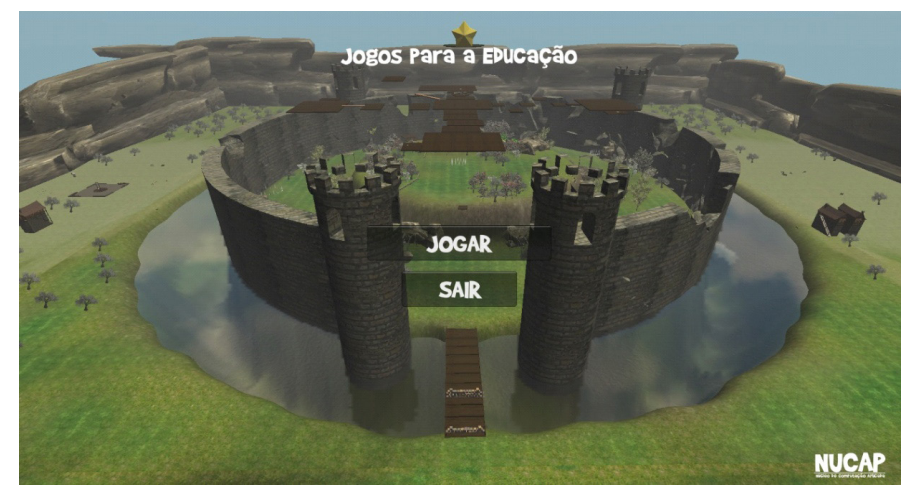

Figura 1: Tela inicial do jogo Estrela do Saber. Fonte: NUCAP/UniCarioca.

O jogo foi aplicado na sala dos professores para os participantes desta etapa da pesquisa. Utilizamos os recursos tecnológicos do computador e do Datashow. Após apresentarmos o jogo, dividimos os participantes da pesquisa em dois grupos, para que pudessem criar perguntas a serem inseridas no jogo utilizando o link no módulo do professor. Os dois grupos jogaram coletivamente tentando responder às perguntas criadas pelo grupo adversário.

Os professores envolvidos nesta etapa prática da pesquisa se mostraram entusiasmados com o recurso tecnológico apresentado. Esta etapa teve como finalidade o enriquecimento do aprendizado dos professores para que possam promover novas formas lúdicas, ricas e produtivas de conhecimento e motivação às aulas que ministram, permitindo a troca de conhecimentos entre os alunos envolvidos de maneira a enriquecer cada vez mais os conteúdos das aulas e o uso das novas tecnologias digitais na educação. 


\section{Resultados}

Os resultados apresentados a seguir referem-se ao questionário como instrumento metodológico deste trabalho, aplicado a 52 professores, profissionais da Educação Infantil 1 ao $5^{\circ}$ ano do Ensino Fundamental I, no município do Rio de Janeiro.

Em relação ao perfil dos professores, foi possível observar que 99\% são do gênero feminino, com idades entre 20 e 60 anos, $86 \%$ deles possuem formação superior em licenciatura e 3\% em nível médio. Em relação ao tempo de serviço, constatou-se que varia de 2 a 43 anos de atuação.

\section{QUADRO DEMONSTRATIVO DOS RESULTADOS DA PESQUISA}

\begin{tabular}{|c|c|}
\hline Questões & Total: 52 entrevistados \\
\hline \multirow{3}{*}{$\begin{array}{l}\text { 1. Sobre a existência de } \\
\text { laboratório de informática na } \\
\text { escola. }\end{array}$} & $\begin{array}{l}9,61 \% \text { confirmaram que a escola } \\
\text { possui laboratório de informática } \\
\text { em funcionamento. }\end{array}$ \\
\hline & $\begin{array}{l}67,3 \% \text { registraram possuir labo- } \\
\text { ratório de informática, porém } \\
\text { obsoletos ou desativados. }\end{array}$ \\
\hline & $\begin{array}{l}23 \% \text { afirmaram que não há labo- } \\
\text { ratório de informática em suas } \\
\text { respectivas escolas. }\end{array}$ \\
\hline \multirow{3}{*}{$\begin{array}{l}\text { 2. Trata-se do acesso à internet } \\
\text { pela escola. }\end{array}$} & $\begin{array}{l}100 \% \text { dos entrevistados informa- } \\
\text { ram que a escola em que traba- } \\
\text { lham possui acesso à internet. }\end{array}$ \\
\hline & $\begin{array}{l}46,1 \% \text { dos professores têm aces- } \\
\text { so à internet na unidade escolar } \\
\text { voltado para fins pedagógico. }\end{array}$ \\
\hline & $\begin{array}{l}53,9 \% \text { dos entrevistados afirmam } \\
\text { que o acesso à internet é restrito } \\
\text { à gestão da escola. }\end{array}$ \\
\hline \multirow{5}{*}{$\begin{array}{l}\text { 3. Investiga os tipos de recursos } \\
\text { tecnológicos utilizados em sala } \\
\text { de aula. }\end{array}$} & $\begin{array}{l}63 \% \text { dos docentes utilizam o Da- } \\
\text { tashow e notebook com frequên- } \\
\text { cia em suas aulas. }\end{array}$ \\
\hline & $\begin{array}{l}5 \% \text { dos entrevistados utilizam o } \\
\text { tablet. }\end{array}$ \\
\hline & 15\% utilizam o rádio. \\
\hline & $10 \%$ utilizam a televisão. \\
\hline & $\begin{array}{l}\text { Nenhum dos entrevistados afir- } \\
\text { mou possuir tela interativa. }\end{array}$ \\
\hline
\end{tabular}




\begin{tabular}{|c|c|}
\hline \multirow{3}{*}{$\begin{array}{l}\text { 4. A respeito ao sentimento do } \\
\text { educador em estar preparado } \\
\text { frente às novas tecnologias. }\end{array}$} & $\begin{array}{l}19 \% \text { não utilizam recurso tecno- } \\
\text { lógico em sala de aula. }\end{array}$ \\
\hline & $\begin{array}{l}58 \% \text { dos participantes da pesqui- } \\
\text { sa afirmaram que estão } \\
\text { preparados para atuar frente às } \\
\text { novas tecnologias. }\end{array}$ \\
\hline & $\begin{array}{l}42 \% \text { dos professores não estão } \\
\text { preparados para atuarem } \\
\text { utilizando as novas tecnologias. }\end{array}$ \\
\hline \multirow{3}{*}{$\begin{array}{l}\text { 5. Aborda a forma com a qual } \\
\text { o professor avalia a relação dos } \\
\text { seus alunos frente às novas } \\
\text { tecnologias. }\end{array}$} & $\begin{array}{l}73 \% \text { dos professores afirmam que } \\
\text { os alunos estão sempre } \\
\text { conectados. }\end{array}$ \\
\hline & $\begin{array}{l}24 \% \text { afirmaram que ainda } \\
\text { existem crianças sem acesso aos } \\
\text { recursos digitais. }\end{array}$ \\
\hline & $\begin{array}{l}3 \% \text { responderam que os alunos } \\
\text { são indiferentes às novas } \\
\text { tecnologias. }\end{array}$ \\
\hline \multirow[b]{2}{*}{$\begin{array}{l}\text { 6. Se o entrevistado acredita que } \\
\text { o uso das tecnologias melhora o } \\
\text { processo de aprendizagem. }\end{array}$} & $\begin{array}{l}\text { 99\% dos professores responde- } \\
\text { ram que sim. }\end{array}$ \\
\hline & $\begin{array}{l}\text { 1\% dos entrevistados não acre- } \\
\text { dita que o uso das tecnologias } \\
\text { melhora o processo de aprendi- } \\
\text { zagem. }\end{array}$ \\
\hline \multirow{2}{*}{$\begin{array}{l}\text { 7. Refere-se sobre a rede de ensi- } \\
\text { no em que o professor trabalha e } \\
\text { se ela oferece formação conti- } \\
\text { nuada em serviço na temática } \\
\text { abordada pela pesquisa. }\end{array}$} & $\begin{array}{l}17 \% \text { recebem formação conti- } \\
\text { nuada sobre o uso das novas } \\
\text { tecnologias em sala de aula. }\end{array}$ \\
\hline & $\begin{array}{l}\text { 83\% não tiveram formação } \\
\text { continuada em serviço voltado } \\
\text { para a temática do uso das novas } \\
\text { tecnologias em sala de aula. }\end{array}$ \\
\hline \multirow{2}{*}{$\begin{array}{l}\text { 8. Investiga sobre o incentivo por } \\
\text { parte da gestão quanto ao uso } \\
\text { das novas tecnologias em sala } \\
\text { de aula. }\end{array}$} & $\begin{array}{l}68 \% \text { afirmaram que a gestão } \\
\text { escolar incentiva o uso das novas } \\
\text { tecnologias em sala de aula. }\end{array}$ \\
\hline & $\begin{array}{l}32 \% \text { relataram que não recebem } \\
\text { o referido incentivo. }\end{array}$ \\
\hline \multirow{2}{*}{$\begin{array}{l}\text { 9. Refere-se ao estudo de alguma } \\
\text { disciplina ou conteúdo em sua } \\
\text { formação acadêmica relacionada } \\
\text { ao uso das tecnologias em sala } \\
\text { de aula. }\end{array}$} & $\begin{array}{l}44 \% \text { dos participantes tiveram } \\
\text { acesso ao conteúdo relacionado } \\
\text { às novas tecnologias durante a } \\
\text { formação acadêmica. }\end{array}$ \\
\hline & $\begin{array}{l}56 \% \text { dos entrevistados durante a } \\
\text { formação acadêmica não tiveram } \\
\text { acesso ao uso das tecnologias em } \\
\text { sala de aula. }\end{array}$ \\
\hline
\end{tabular}




\section{Discussão}

Realizamos uma análise crítica dos resultados descritos acima e observamos que o perfil dos professores nos remete a uma visão mais significativa por parte dos professores que acreditam na importância das novas tecnologias presentes no âmbito escolar.

O questionário aplicado foi constituído por nove questões sobre a temática "Formação Continuada dos Professores e as Novas Tecnologias" para profissionais que atuam da Educação Infantil ao $5^{\circ}$ ano de escolaridade, na rede Municipal do Rio de Janeiro. Podemos afirmar, nessa discussão, que a maioria dos professores regentes não tem acesso às tecnologias digitais em sala de aula.

Apesar da falta de conhecimentos práticos mínimos para a inserção e aplicação das tecnologias em sala de aula, a maioria dos professores afirma que o uso das novas tecnologias enriquece o processo ensino aprendizagem.

Constatamos que o acesso ao computador e à internet é, em muitas situações, apenas ofertado à gestão da escola, o que dificulta a prática de um possível trabalho diferenciado que permita a inserção do aluno além do espaço físico escolar. É fundamental que a gestão escolar colabore e apoie o uso das tecnologias, com suas ferramentas e interfaces, no enriquecimento do processo ensino aprendizagem.

Após todas as questões acima lançadas, foi desenvolvida a última etapa prática desta pesquisa, objetivando apresentar uma ferramenta tecnológica para que possa ser inserida futuramente pelos professores em suas salas de aulas. Nesta etapa, apenas dezenove professores aceitaram ou tiveram disponibilidade de tempo para participar da parte prática da pesquisa.

Utilizamos essa estratégia para sensibilizá-los sobre a utilização do recurso tecnológico no processo ensino aprendizagem. Os jogos digitais podem ir além do que imaginamos, valendo-se apenas de uma proposta e um planejamento adequado.

Finalmente, a discussão demonstra que os professores não utilizam as novas tecnologias, porque não têm ferramentas tecnológicas disponíveis ou elas estão obsoletas. Deve-se destacar, também, que a maioria dos profissionais não recebe formação continuada para a utilização dos recursos digitais como instrumento complementar da prática pedagógica desenvolvida com os alunos.

\section{Considerações Finais}

Este trabalho investigou os resultados encontrados a partir da realidade das escolas públicas quanto ao uso das novas tecnologias, assim como identificou alguns motivos que levam grande parte dos professores a restringirem o seu trabalho aos métodos tradicionais de ensino.

O estudo dos autores citados neste trabalho vem ao encontro dos nossos anseios sobre a pesquisa da realidade atual das escolas, nas quais, apesar da incontestável mudança de perfis cognitivos, ainda não há o necessário espaço para a realidade tecnológica e digital da atual sociedade. É notória a preocupação dos professores quanto à necessidade de mudanças na sala de aula, pois estão cientes de que o ensino tradicional não é mais capaz de aguçar o prazer pela aprendizagem dos alunos. Apesar dessa visão realista, as condições das escolas são mínimas em face da realidade necessária.

Constamos, assim, a importância das ferramentas tecnológicas no ambiente escolar. Contudo é importante ressaltarmos que a formação adequada do professor atrelada à aplicação das tecnologias em sua plenitude é também um dos passos para fazer da sala de aula um ambiente melhor. Para isso, o professor deve mudar seu olhar quanto às tecnologias para que elas se tornem aliadas e não empecilhos.

O objetivo de se trabalhar com as tecnologias não se refere a usá-las a qualquer custo, pois se a mente do professor não estiver aberta às possibilidades dos recursos, as aulas permanecerão atreladas ao ensino tradicional, independentemente de ser o recurso mais atualizado e com capacidade ímpar.

Segundo os dados colhidos, os cursos de formação de professores ainda não têm como parte do componente curricular disciplinas voltadas para o ensino das novas tecnologias como ferramenta didática e pedagógica para ser utilizada nos espaços educativos e culturais formais e não formais.

Concluímos que o uso das novas tecnologias no processo educacional ainda não é uma realidade presente no cotidiano 
escolar. Precisamos de investimentos tanto na formação continuada do professor como também em equipamentos e utilização das novas tecnologias digitais na educação, para que possamos potencializar todas as formas e processos de aprendizagem.

\section{Referências Bibliográficas}

BRASIL- Ministério da Educação. Manual de Inovações Tecnológicas Na Educação: Contribuições para Gestores Públicos (2014). Todos pela Educação. Instituto Inspirare. Disponível em https://s3.amazonaws.com/porvir/wp-content/uploads/2014/08/Inova\%C3\%A7\%C3\%B5es-Tecnol\%C3\%B3gicas-na-Educa\%C3\%A7\%C3\%A3o_Contribui\%C3\%A7\%C3\%B5es-para-gestores-p\%C3\%BAblicos_2014.pdf,acesso em 28 de setembro de 2017.

- Ministério da Educação; Parâmetros Curriculares Nacionais- Ensino Médio; Brasília: MEC/Secretaria de Educação Básica, 2000.

FREITAS, Maria Teresa. Letramento Digital e Formação de Professores. Educação em Revista, Belo Horizonte, v.26, n.03, p.335- 352, dezembro 2010.

KENSKI, V. M.. Tecnologias e ensino presencial e a distância. Campinas: Papirus, 2003.

Educação e Tecnologias. O Novo Ritmo da Informação. Campinas: Papirus, 2012.

LÉVY, Pierre. Cibercultura. Tradução de Carlos Irineu da Costa. São Paulo: Ed. 34, 1999.

MORAN, J. M.; MASETTO, M. T.; BEHRENS, M. A. Novas tecnologias e mediação pedagógica. Campinas: Papirus, 2001.

MORAN, J. M. O Uso das Novas Tecnologias da Informação e da Comunicação na EAD - uma leitura crítica dos meios. Disponível em: http://portal. mec.gov.br/seed/arquivos/pdf/T6\%20TextoMoran.pdf. Acesso em 14 de novembro de 2017.

MORIN, E. Ciência com Consciência. Rio de Janeiro: Bertrand Brasil, 1996.

PRIKLADNICKI, R.; WANGENHEIM, C.G. O Uso de jogos educacionais para o ensino de gerência de projetos de software. In: FÓRUM DE EDUCAÇÃO EM ENGENHARIA DE SOFTWARE, 1., Fortaleza. Anais eletrônicos. Pág.37. Rio de Janeiro: PUC, 2008. Disponível em: <ftp://ftp.inf.pucrio.br/pub/ docs/techreports/08_43_leite.pdf>; Acesso em 03 de dez. 2017.

\section{Contato dos autores}

Ana Márcia da Silva Vieira | anamsvieira17@hotmail.com Débora Alves Morra Loures | damloures@yahoo.com.br Paloma Mendes Flores Brandão | palomaflores1989@gmail.com

Antônio Carlos de Abreu Mol |amol@unicarioca.edu.br Ana Paula Legey de Siqueira | asiqueira@unicarioca.edu.br Marco Antonio Silva | msilva@unicarioca.edu.br Victor Gonçalves Freitas | vfreitas@unicarioca.edu.br 